\title{
Work/Careers
}

"Early-career researchers are like cannon fodder," she says. "They're used for a few years while they're cheap. They're dispensable."

In a similar vein, $60 \%$ of respondents said they had been negatively affected by a lack of support from institutional leaders. Vaux says that most early-career researchers in Australia are funded not by their home institutions, but by external grants and other forms of 'soft money' that do not include paid salaries. He adds that established scientists are often too concerned about their own job security to truly mentor the next generation. "Most principal investigators are treading furiously to keep their heads above water," he says.

\section{Need for change}

The survey's authors note that Australian science could suffer if these issues are not addressed. Pressures compromising training and career progression "may contribute to a decay in research quality", they write.

"The soft-money aspect of the culture is always a challenge," says Drew Dawson, a psychologist at Central Queensland University in Adelaide. “I didn't get my first hard-money position until I was 53." But he also says that

\section{“They're satisfied with their work, but they're not satisfied with their workplace."}

respondents might not have a full picture of the state of Australian science. "Research culture varies from lab to lab," he says. "People don't necessarily know the diversity of opportunities that exist."

When asked why they stay in science, many respondents highlighted the positive side of research. One wrote, "I am passionate about my work and driven to make a difference." Another answered, "I love research! No two days are the same."

Respondents were also asked if they found their work to be rewarding overall, and $77 \%$ answered positively. "They love what they do," Christian says. "They're satisfied with their work, but they're not satisfied with their workplace."

As a result, many respondents have felt uneasy with their career paths. Nearly $80 \%$ had considered a major change of career or position in the previous five years; nearly $20 \%$ of all respondents said they had considered leaving Australia.

"The research institutions are as good as they can be anywhere in the world," Doran says, "but many people still have the perception that you need to go overseas."

Chris Woolston is a freelance writer in Billings, Montana.

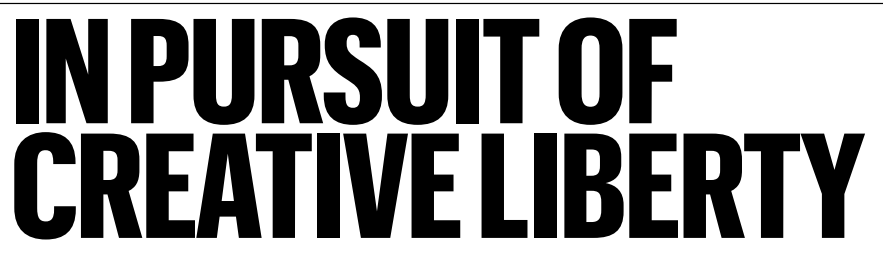

\section{Skills developed as a government scientist were useful during a PhD. By Rachel Ragnhild Carlson}

pr n my past two years as a PhD student, I've had time to unpack how I feel about my previous position as a scientist at the US Environmental Protection Agency (EPA). I worked there for four years as an environmental protection specialist, during which I analysed pollution in sources of drinking water and led programmes to protect coastal ecosystems. I left one year after President Donald Trump's appointee Scott Pruitt took office as administrator.

While at the EPA, I developed powerful skills that serve me well as a PhD student. Here's what I've learnt.

A few months ago, my $\mathrm{PhD}$ adviser asked me to draft a flyer for the public on our research in marine ecology. After reading my draft, he wrote, “Oh my gosh. You made this?!” The flyer was distributed to thousands.

His surprise, in turn, surprised me. At the EPA, communications skills are an entry-level requirement for many scientists: our ability to reach constituents is crucial. My colleagues and I constantly took pains to deliver not only sound science, but flashy materials to convince all Americans that we were a friend, not a foe. It became second nature for me to adapt technical data for use in a web app, presentation or radio jingle.

As a PhD student at Stanford University, California, and at Arizona State University in Tempe, I've come to realize the value of this versatility. Naysayers come in many forms: they can be coal lobbyists, penetrating reviewers or honest farmers trying to earn a living. Researchers' output is at its most powerful when aided by a full set of tools designed to reach every one of these people.

\section{Embrace setbacks}

One of my EPA colleagues helped to develop an environmental policy to control water pollution that was rolled out under Barack Obama's administration - only to be dismantled after Trump took the helm. Such challenges happen in academia, too: we all face dysfunctional experiments and rejected manuscripts. But in public service, you are reminded that failures come and go with elections. At the EPA, we marked time with administrations. For each of us, the administration during which we began our employment became our initiation into a reality in which idealism

\section{means, ultimately, patience.}

I remember this lesson now, as a PhD student. Each new generation of scientists confronting climate change must strive persistently towards environmental solutions, but we must also assume frequent failures because these fuel our successes.

Government agencies are famous for providing career stability. Some of my colleagues at the EPA had worked there since its inception in 1970. When I began a new project, I would mine the agency's online databases but would also chat with senior employees, who were often a better source of the information I needed. Their historical knowledge could uncover a buried protocol or crucial record more efficiently than my search engines could.

As a PhD student, I've learnt to rely not just on my Web of Science research, but on conversations with experts. And my reading includes literature from previous decades. This practice is reinforced by my mentors, who often find research gems by filtering explicitly for yearsold studies.

\section{Seize creative freedom}

At the EPA, I acted on behalf of an agency that, in turn, represented the interests of the US public. To represent the Pruitt administration was a task apart. The research I pursued at the agency was shaped by legal mandates and public opinion - and, under Pruitt, by a leadership that sapped morale through budget cuts, lay-offs and efforts to weaken regulations. For example, I coordinated a grant that was withheld until I formally removed all instances of the phrase 'climate change'. Throughout my time there, my creative freedom was limited.

Now, my work feels unconstrained - guided by my own curiosity and sense of purpose. I spend my time measuring, analysing, reading and writing about the topic I love most, surrounded by inspiring people who support my goals. In an era of politicized science, our time as $\mathrm{PhD}$ students is a rare and radical period of intellectual liberty. This is yet another reason for every institution to defend graduate training as the positive and imaginative experience that it deserves to be.

Rachel Ragnhild Carlson is a PhD student at Stanford University, California, and Arizona State University in Tempe. 